\title{
Dynamic Response of Structure under Blast Load
}

\author{
Daniel Makovicka $^{1}$ and Jr. Daniel Makovicka ${ }^{2}$ \\ 1. Department of Mechanics, Klokner Institute, Czech Technical University, Prague CZ 166 08, Czech Republic \\ 2. Static and Dynamic Consulting Firm, Kutna Hora CZ 284 01, Czech Republic
}

\begin{abstract}
The paper follows from the theory of explosion and interaction of an impact wave formed by the explosion and a structure. Firstly, the paper determines the parameters of the blast wave excited by a small charge explosion. The empirical formulas on the basis of our own experimental results are shown and used for the structure analysis. Evaluations of structures loaded by an explosion based on dynamic response in rotations round the central line of plate or beam systems during the dynamic load of this type is discussed in the paper and comparison of own limit values and published ones is presented. Blast loads typically produce very high strain rates $\dot{\varepsilon}$ in the range of $10^{-2}$ to $10^{-4} \mathrm{~s}^{-1}$. The effect of strain rate for concrete material is discussed. The formulas for increased compressive strength of concrete and steel reinforcement are presented. The ductility of structural members is influenced by the corresponding values under high strain rate of reinforcement. Damage to the structure is assessed accordingly firstly by the angle of rotation of the middle axis/surface, and secondly by the limit internal forces of the selected structure. The extreme nature of blast resistance makes it necessary to accept that structural members have some degree of inelastic response in most cases. This enables the application of structure dissipation using the ductility factor and increased of concrete strength. The limits are correlated with qualitative damage expectations. The methodology of dynamic response assessment and its application to the simple bridge structure is discussed.
\end{abstract}

Key words: Explosion, blast wave, dynamic load, response, assumption, bridge structure.

\section{Introduction}

Evaluation of safety and reliability of building structure, particularly based on experience gained worldwide and today also based on Eurocodes, requires that some structures be designed for extraordinary loads caused by external influences. Explosion load [1] is also one of such influences, caused usually by an explosion of condensed explosives in the outside environment. Intensity and course of blast wave in time are given by chemical properties of the explosive (flammable) substance or by the physical state of the substance and its reactions with the surrounding environment.

The blast wave starts propagate from the point of explosion approximately in spherical wave fronts, and upon hitting the surface of a building structure or terrain, the wave front is reflected and modified. The

Corresponding author: Daniel Makovicka, D.Sc., associate professor, research fields: statics, dynamics of structures, earthquake, explosion and effects of machines. action of pressure in the propagated wave, together with the pressure wave reflected from the surface of a structure or terrain, determines the magnitude of the structure load and its course in time.

In the process of evaluating the building structure response to the effects of an explosion, specific conditions of the given locality and of the building structure should be considered, based on which the structure response to explosion load can be estimated, either more accurately by a calculation or approximately on the basis of our own experimental results [2].

Properties of the structure, as a unit or of its parts and its materials, are decisive for the magnitude and nature of the response of any explosion loaded structure. These include particularly mechanical characteristics of the material (especially its strength, way of failure, stress-strain diagram, behaviour beyond the elasticity limit, etc.), and distribution of masses and structure rigidity with corresponding frequency tuning of the structure, characteristics of 
surfaces loaded by the impact blast wave, structure geometry compared to explosion wave characteristics, any previous failures of the structure, including changes in the structure material properties in the course of time for existing structures, etc. [3, 4].

Evaluations of structures loaded by an explosion based on dynamic response in rotations round the central line of plate or beam systems during the dynamic load of this type is discussed in the paper and comparison of own limit values and published ones is presented.

\section{Load}

When a charge explodes in an open space, the pressure effect of the impact wave on an obstacle (the load of the structure) depends on the situation of the structure with respect to the focus of the explosion, the impact wave parameters, etc. The entire phenomenon of the impact wave effect on the structure is then usually simplified for calculation purposes, using numerous assumptions, especially as regards the intensity and the time course of the impact wave effect and its distribution in contact with the given object [1]:

(1) Triangle-shaped development of the load in time with the maximum intensity corresponded to the sum of the pressures of the impacting and reflected waves and the duration of the action, usually corresponded only to the duration of the action of the overpressure phase of the shock wave;

(2) The shock wave can be considered as having a flat front, meaning that the rise time to maximum intensity is neglected, and additionally that the load starts to act on the entire structure at one moment. The phase shift of the start of the action of the load at individual structure points is thus neglected;

(3) It is usually assumed that the load acts on the building structure in a continuous and uniform manner (any local effect of the focused load is neglected);

(4) The response of the structure is usually considered on the basis of the superimposition of two triangular loads, which correspond to the overpressure phase and subsequently the underpressure phase of the shock wave.

In case of explosions of gaseous mixtures (in contradiction to the explosions of charges of solid or liquid explosives) apart from the triangular overpressure phase, also the underpressure phase is significant, the effect of which can be repeatedly considered as fast triangular loads, but with the opposite sign and a phase shift. Both phases (overpressure and underpressure) may be considered separately in such a way as would enable the superposition of obtained results of both phases to obtain total effects.

When an actual event takes place, the specific course of the load action depends on the swirl flow bypassing the structure surface, the atmospheric pressure, the temperature conditions and other factors that are usually neglected in a simplified analysis. The parameters of the explosive, too, are determined on the basis of average values. Empirical formulas are used, and operate with mean (probable) coefficient levels. Thus, the structure calculations concerning the impact wave effects are significantly burdened by these inaccuracies in the input quantities of the entire phenomenon.

Empirical formulas created by various authors $[1,2,5,6]$ are usually used for the time course of the pressure wave and subsequently the structure load. The structure of the formulas according to various authors is very similar, and they usually differ only in the magnitudes of the coefficients. Due to the variability of these coefficients, the uncertainty of the formulas is usually found to be in the range of $\pm 20 \%$, and possibly even more. The reliability of individual formulas improves with increasing distance of the pressure wave from the focus of the explosion.

The overpressure determined at the face of the air impact wave that spreads from the explosion site to the surroundings stems from the reduced distance $[1,2]$ is: 


$$
\bar{R}=R / \sqrt[3]{C_{W}}
$$

where, $\bar{R}$ is the reduced separation distance from the epicentre of the explosion $\left(\mathrm{m} / \mathrm{kg}^{1 / 3}\right), R$ is the distance from the explosion epicentre (m), and $C_{W}$ is the equivalent mass of the charge ( $\mathrm{kg}$ TNT).

It is assumed that the energy released by the explosion is proportional to the mass of the explosive, and the solution consists in introducing a reference charge chosen to be represented by tritol (trinitrotoluene, TNT). Therefore, the mass of various explosives is expressed in terms of the so-called tritol equivalent $\left(k_{\mathrm{TNT}}\right)$. If this equivalent can not be found in the specialized literature, it can be calculated with sufficient accuracy using the relationship:

$$
k_{\mathrm{TNT}-p}=0.3 Q_{v}-0.2 \text { (for } 2 \mathrm{MJ} / \mathrm{kg} \leq Q_{v} \leq 5 \mathrm{MJ} / \mathrm{kg} \text { ) }
$$

where, $k_{\text {TNT- } p}$ is the pressure tritol equivalent of the explosive (equal to 1 for TNT), $Q_{v}$ is the calculated explosion heat $(\mathrm{MJ} / \mathrm{kg})$ and $Q_{v}=4.2 \mathrm{MJ} / \mathrm{kg}$ for TNT.

Then the total equivalent mass $C_{W}$ can be determined using Eq. (2) [2]:

$$
C_{W}=C_{N} \cdot k_{\mathrm{TNT}-p} \cdot k_{E} \cdot k_{G}
$$

where, $C_{W}$ is the mass of the equivalent charge $(\mathrm{kg}$ TNT), $C_{N}$ is the mass of the used charge of the (actual) explosive $(\mathrm{kg}), k_{\mathrm{TNT}-p}$ is the pressure tritol equivalent, $k_{E}$ is the charge seal coefficient, and $k_{G}$ is the geometry coefficient of the impact wave spreading in the space.

The seal coefficient can be determined using Eq. (3):

$$
k_{E}=0.2+0.8 /\left(1+k_{B}\right)
$$

where, $k_{B}$ is the cover mass $(\mathrm{kg})$ divided by the explosive mass $(\mathrm{kg})$, and expresses the ballistic ratio. The following applies to the geometry coefficient $k_{G}$.

The explosion wave spreads in spherical wave fronts from the focused point of the explosion. When the explosion is on the ground, the explosion energy is roughly double because, after complete reflection from the surface of the terrain, the pressure wave spreads in hemispherical wave fronts. The spreading geometry coefficient $k_{G}$ is not stated by some authors in the formulas for determining the total equivalent mass. In such cases, and in the case of a ground explosion, the equivalent charge mass $C_{W}$ is as a rule substituted by twice its value in empirical formulas.

In the simplified calculation [2, 3], a ground explosion is represented by a situation when the explosive is located directly on the surface of the terrain ( $h=0 \mathrm{~m}$ thus $k_{G}=2$ ). An explosion in an open air space is a situation when the delay of the reflected wave from the surface of the terrain to the pressure wave front is higher than the duration of the overpressure phase of the pressure wave $\left(k_{G}=1\right)$. A linear interpolation is made between both values of $k_{G}$.

On the basis of comparing various resources in the literature $[1,2,6]$ and our own results of tests of masonry walls [4] and window glass structures during explosions of small charges, the authors of this paper proposed the application of realistic formulas. The empirical formulas below were verified in experiments using small charges (Semtex) in the vicinity of the loaded structure. Their resulting form then corresponds to the impact wave effects from a small solid charge in an open air during this explosion. Maximum overpressure $p_{+}$and underpressure $p_{-}$at the face of the air impact wave, velocity $v$ of the wave face propagation and its durations $\tau_{+}$and $\tau_{-}$are applicable both to ground and above-ground explosions:

$$
\begin{gathered}
p_{+}=1.07 / \bar{R}^{3}-0.1 \quad(\mathrm{MPa}) \text { for } \bar{R} \leq 1 \mathrm{~m} / \mathrm{kg}^{1 / 3}(4) \\
p_{+}=0.0932 / \bar{R}+0.383 / \bar{R}^{2}+1.275 / \bar{R}^{3}(\mathrm{MPa})(5)
\end{gathered}
$$

for $1<\bar{R} \leq 15 \mathrm{~m} / \mathrm{kg}^{1 / 3}$

$$
\begin{gathered}
p_{-}=0.035 / \bar{R} \quad(\mathrm{MPa}) \\
\tau_{+}=1.6 \cdot 10^{-3} \cdot \sqrt[6]{C_{W}} \cdot \sqrt{R} \quad(\mathrm{~s}) \\
\tau_{-}=1.6 \cdot 10^{-2} \cdot \sqrt[3]{C_{W}} \quad(\mathrm{~s}) \\
v=340 \cdot \sqrt{1+8.3 \cdot p_{+}} \quad(\mathrm{m} / \mathrm{s})
\end{gathered}
$$

After a normal (perpendicular) impact of the explosion wave on a solid obstacle, a reflected wave is formed with the reflection overpressure $p_{\text {ref }}$ that loads the building structure from the front side. The overpressure value in the reflected wave corresponds 
to approximately twice the value of the overpressure for low overpressure values $p_{+}$of approximately up to $5 \mathrm{MPa}$ (up to eight times the value for high overpressures of the order of several $\mathrm{MPa}$ ) in the incident wave for the given distance $R$ [2].

$$
\begin{aligned}
& p_{\text {ref }+} \approx 2 p_{+} \\
& p_{\text {ref- }} \approx 2 p_{-}
\end{aligned}
$$

The duration of the action of the pressure $t_{D}$ is about the same as the duration of blast wave $\tau_{+}$or $\tau_{-}$.

\section{Structure Response}

The structure should be analysed using the following load combinations simplified as an equivalent static analysis (Eq. (12)) or as a dynamic analysis (Eqs. (13) and (14)):

$$
\begin{gathered}
\delta(1.2 D+0.25 L) \\
D+(0.25 \text { or } 0.50) L
\end{gathered}
$$

or for alternate load path method (checking if residual load carrying capacity upon notional removal of a selected load bearing element):

(0.9 or 1.2$) D+(0.5 L$ or $0.2 S)+0.2 W_{n}$

where, $D$ is dead load (1.2 $D$ or $1.0 D$ is usually recommended), $L$ is live load, $S$ is snow load for roof, $W_{n}$ is wind load for periphery structure elements, $\delta \approx 1 \sim 2$ is dynamic load factor (DOD UFC [7] recommends $\delta=2.0$; Other publications conclude that the use of a fixed dynamic load factor of 2.0 is highly conservative).

When a structure is loaded by an explosion, the formation of cracks not leading to a collapse is as a rule permitted. Thus ductility factor $q$ may be used to reduce the magnitude of the explosion load. This is a highly efficient way of taking inelastic manifestations of the dynamic load into account:

$$
q=x_{m} / x_{e l}
$$

where, $x_{m}$ is the maximum elastic plastic displacement of the structure, and $x_{e l}$ is the elastic part of the displacement.

The applicable ductility factor is usually $q<3$ for reinforced concrete structures (On the basis of a more detailed analysis of the structure, higher ductility factor
Table 1 Estimation of factor $k_{1}$ in dependence on load duration $t_{D}$ for concrete.

\begin{tabular}{lcccc}
\hline \multicolumn{4}{l}{ Factor and load duration } \\
\hline$t_{D}(\mathrm{~s})$ & $\geq 1.0$ & $10^{-1}$ & $10^{-2}$ & $10^{-3}$ \\
$k_{1}$ & 1.0 & 1.05 & 1.10 & 1.20 \\
\hline
\end{tabular}

values may be used, for example, on the basis of seismic standard EN 1998-1).

The strength characteristics of the structure material may also be increased in the calculation of the structure response. An estimate of this increase (minimum material strengthening factor $k_{1}$ ) is shown in Table 1 [8], in dependence on the duration of the explosion load $t_{D}$.

Blast loads usually produce very high strain rates in the range of $10^{-2}$ to $10^{-4} \mathrm{~s}^{-1}$. In comparison with Table 1 , this strain rate would increase the stress and strain capacities of concrete and its steel reinforcement [9]. The increased compressive strength $f_{c d}^{\prime}$ of concrete under dynamic loading can be calculated as:

$$
\begin{gathered}
f_{c d}^{\prime}=f_{c}^{\prime} K_{d} \\
K_{d}(\varepsilon)=\left(\dot{\varepsilon} / \dot{\varepsilon}_{s}\right)^{1.026 \alpha} \text { for } \dot{\varepsilon} \leq 30 \mathrm{~s}^{-1} \\
K_{d}(\varepsilon)=\gamma\left(\dot{\varepsilon} / \dot{\varepsilon}_{s}\right)^{1 / 3} \text { for } \dot{\varepsilon}>30 \mathrm{~s}^{-1} \\
\log \gamma=6.156 \alpha-2 \\
\alpha=1 /\left(5+9 f_{c}^{\prime} / f_{c o}^{\prime}\right)
\end{gathered}
$$

where, $\dot{\varepsilon}$ is the strain rate, $\dot{\varepsilon}_{s}$ (quasi-static strain rate) is $30 \times 10^{-6} \mathrm{~s}^{-1}, f_{c o}^{\prime}$ is the reference strength set as $10 \mathrm{MPa}$ and $f_{c}^{\prime}$ is 28-day compressive strength of concrete at static strain rate.

Steel reinforcement also shows higher strength and ductility under high strain rate. Soroushian and Choi [10] proposed a model for stress-strain response of steel under various loading rates. They reported that the increase in steel yielding stress, ultimate strength, and ultimate strain are proportional to the logarithmic function of the strain rate, as follows:

$$
\begin{aligned}
& \frac{f_{y}^{\prime}}{f_{y}}=\left(-0.451 \times 10^{-6} f_{y}+1.46\right)+\left(-9.20 \times 10^{-7} f_{y}+0.093\right) \log _{10} \dot{\varepsilon} \\
& \frac{f_{p}^{\prime}}{f_{p}}=\left(-6.83 \times 10^{-6} f_{y}+1.72\right)+\left(-1.37 \times 10^{-6} f_{y}+0.144\right) \log _{10} \dot{\varepsilon} \\
& \frac{\varepsilon_{u}^{\prime}}{\varepsilon_{u}}=\left(-8.93 \times 10^{-6} f_{y}+1.4\right)+\left(-1.79 \times 10^{-6} f_{y}+0.0834\right) \log _{10} \dot{\varepsilon}
\end{aligned}
$$


where, $f_{y}, f_{p}$ and $\varepsilon_{u}$ are the yielding strength, ultimate strength, and ultimate strain of steel reinforcement under static loading, respectively; and $f_{y}^{\prime}, f_{p}^{\prime}$ and $\varepsilon_{u}^{\prime}$ are their corresponding values under high strain rate of $\dot{\varepsilon}$.

For example for concrete $\mathrm{C} 35 / 45$ and for $t_{D}=0.002 \mathrm{~s}$ are standard recommendations for concrete: Czech: strengthening factor $k_{1}=1.20$ [8] and U.S.: over strength factor $\Omega=1.25$ [7]. According to CEB-FIB [9], $K_{d}=1.29$ (the stress $f_{c}^{\prime}=40 \mathrm{MPa}$ increases to $f_{c d}^{\prime}=51.2 \mathrm{MPa}$ ) and for reinforcement $10505\left(f_{y}=490 \mathrm{MPa}, f_{p}=550 \mathrm{MPa}\right)$ :

$$
f_{y}^{\prime} / f_{y}=1.44 \quad f_{p}^{\prime} / f_{p}=1.68 \quad \varepsilon_{u}^{\prime} / \varepsilon_{u}=1.38
$$

It means that the approximation of strain rate by factors $k_{1}$ and $\Omega$ for concrete stress characteristics is relatively convenient and safety enough.

\section{Response Assumption}

The magnitudes of the internal forces in the analysed structure are considered as a part of the evaluation of the limit bearing capacity conditions, based on load combinations when they are reduced using ductility factor $q$. The resulting internal forces are then evaluated on the basis of design standards for the appropriate structure material type, or as a variant, also according to its increased strength using factor $k_{1}$.

However, this procedure entails two important uncertainties in the case of bent structures, i.e., a suitable choice of the ductility factor, on the one hand, and the material strengthening factor, on the other. During very rapid reshaping of the structure, which is typical for explosion loads, both factors may achieve numeric values of the order of tens, and not only of units, as mentioned above. Thus, they may lead to considerable overdesigning of the structure.

Evaluations of structures loaded by an explosion based on dynamic displacements and rotations round the central line of plate, wall or beam systems during the action of a dynamic load of this type have been of very topical interest in recent times, as regards the process of evaluating the effects of an explosion on a structure. The dynamic rotation round the central line of an appropriate structure element is therefore the criterion used to evaluate the response occurring at the following angle:

$$
\psi=\operatorname{arctg}\left(x_{\mathrm{m}} /\left(0.5 h_{\text {span }}\right)\right)
$$

where, $x_{\mathrm{m}}$ is the maximum achieved dynamic displacement caused by the explosion load and $h_{\text {span }}$ is the span of the plate ceiling structure or the height of the wall structure within one storey, or the span of any beam, the height of a column, etc. The authors applied this procedure to various types of materials and structure systems, and on the basis of an experimental comparison, they determined the failure angle $\psi_{\max }$, i.e., the angle where damage is caused to the structure by breaking (Table 2).

\section{Response of Bridge Structure}

As an example, the reinforced concrete bridge structure was used. The bridge includes four long spans $(30 \mathrm{~m}, 2 \times 45 \mathrm{~m}, 30 \mathrm{~m})$ with intermediate piers $(12.25 \mathrm{~m}, 17.25 \mathrm{~m}, 15.25 \mathrm{~m})$ and was made of concrete C 30/37. The computational model and its cross sections in the middle of spans and in supports are illustrated in Fig. 1. The bridge was analyzed under

Table 2 Limit failure angle $\psi_{\max }\left({ }^{\circ}\right)$ upon breaking of the material.

\begin{tabular}{lll}
\hline Type & Structure material & $\psi_{\max }\left({ }^{\circ}\right)$ \\
\hline 1 & Concrete C16/20 to C40/50 & 6.5 \\
2 & Masonry, full bricks 10, mortar 4 or mortar 10 & 5.0 \\
3 & Masonry, cement bricks, mortar 4 & 4.5 \\
4 & Masonry, cellular concrete or perforated precise blocks, mortar 4 & 4.0 \\
5 & Steel S235 & 10.5 \\
6 & Wood, hard and soft & 12 \\
7 & Window glass, thickness 3 mm & 6 \\
\hline
\end{tabular}




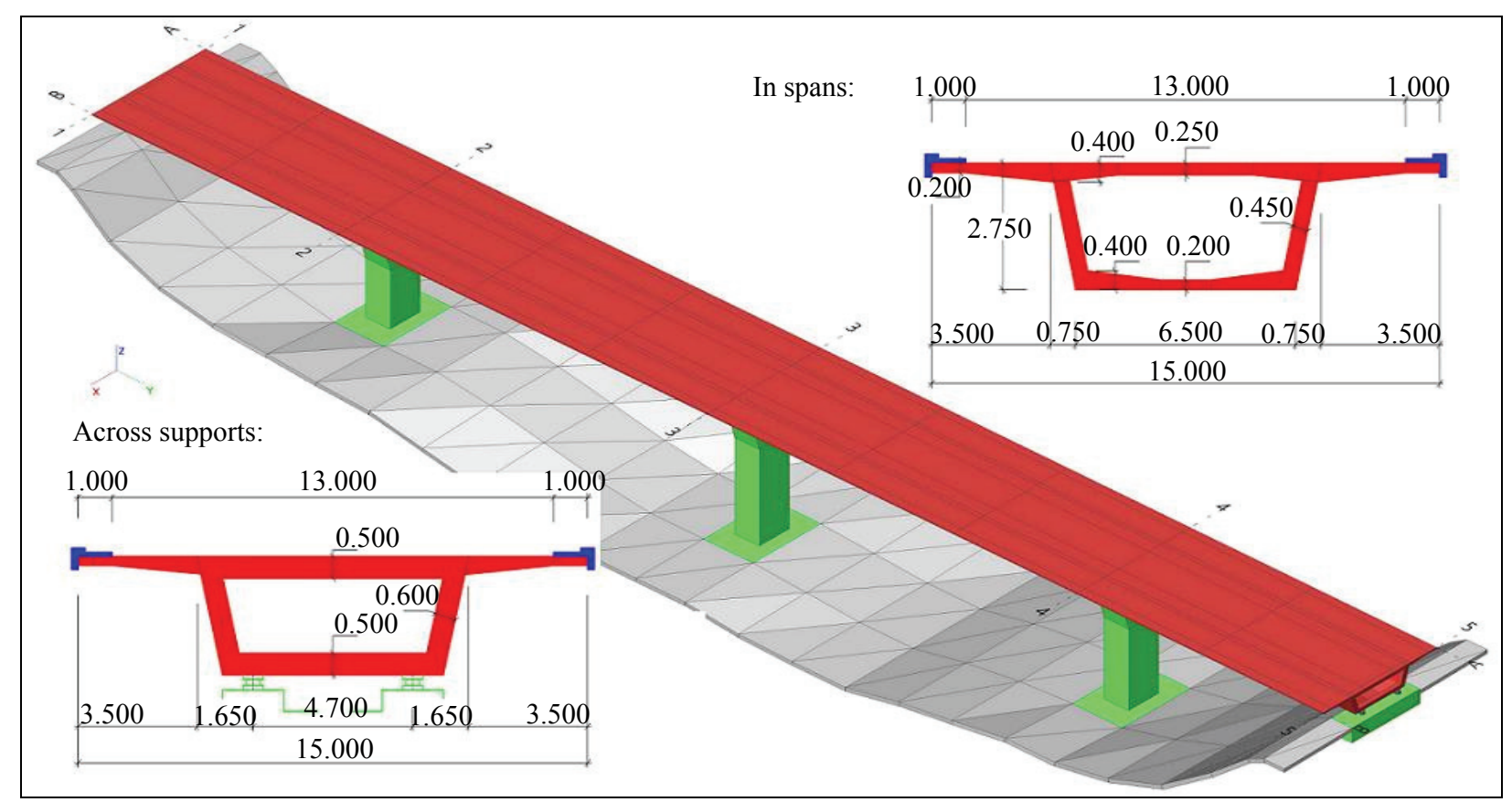

Fig. 1 Bridge structure (unit in $\mathbf{m}$ ).

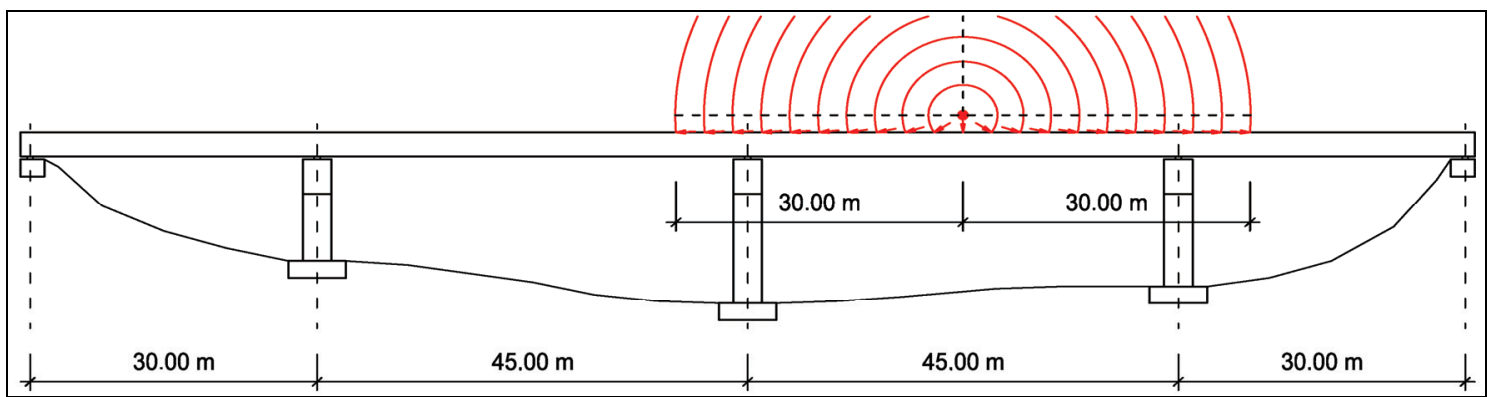

Fig. 2 Location of explosion.

blast load of the explosion $100 \mathrm{~kg}$ TNT above the mid span above the bridge floor in height of $2 \mathrm{~m}$. The dimensions and distribution of structure parts were modelled while respecting the structure geometry and its dimensions, in order to obtain the most precise model of the bridge's mass and stiffness. Besides bridge dead load, the mass of asphalt part of the roadway were included in the bridge mass.

The blast load exerted on bridge floor surface was considered as series of blast histories (by Eqs. (5-10)) acting in the selected points of central part of the floor span (Fig. 2) and graduated in 10 zones in terms of intensity as well as the whole history action on the basis of the real overpressure and underpressure phase of blast wave-dynamic load histories, as a function of the impact wave velocity of propagation [9].
One hundred lowest natural modes and frequencies of vibration in the interval $1.9 \mathrm{~Hz}$ to $21.6 \mathrm{~Hz}$ were considered in the computation. The decomposition of dynamic load history to the natural modes of vibration is used for the forced vibration analysis by means of Scia Engineer Program. The damping of the structure of the building has been set as a damping ratio of $4 \%$. For higher natural frequencies, the damping is usually higher, but the computer program does not allow setting a different damping for these higher frequencies.

The calculation of forced vibration has been made with 1,000-time steps of $0.0005 \mathrm{~s}$. The dynamic response is calculated respectively for each time step. The dynamic analysis was made for linear elastic behaviour of the structure material. 
As an example of the bridge deformation, isolines of vertical displacements of the bridge floor are shown in Fig. 3. Fig. 4 presents angle of rotations in the bridge floor and Fig. 5 indicates time histories in displacements at selected points in the middle of span (in the central part of the roadway and on the boundaries of pavements).

The calculated rotations (angle $\psi$ ) of the middle surface of structural parts are used for structure assessment. The maximal angle of the rotation is 1.9 degrees round the both horizontal axes.

From all the rotations it is clear that in the concrete part of the bridge cross section the failures may occur. The concrete bridge structure responds to the medium structure hazard (the supposed angle of failure is fast one third of limit value), but due to the local damage

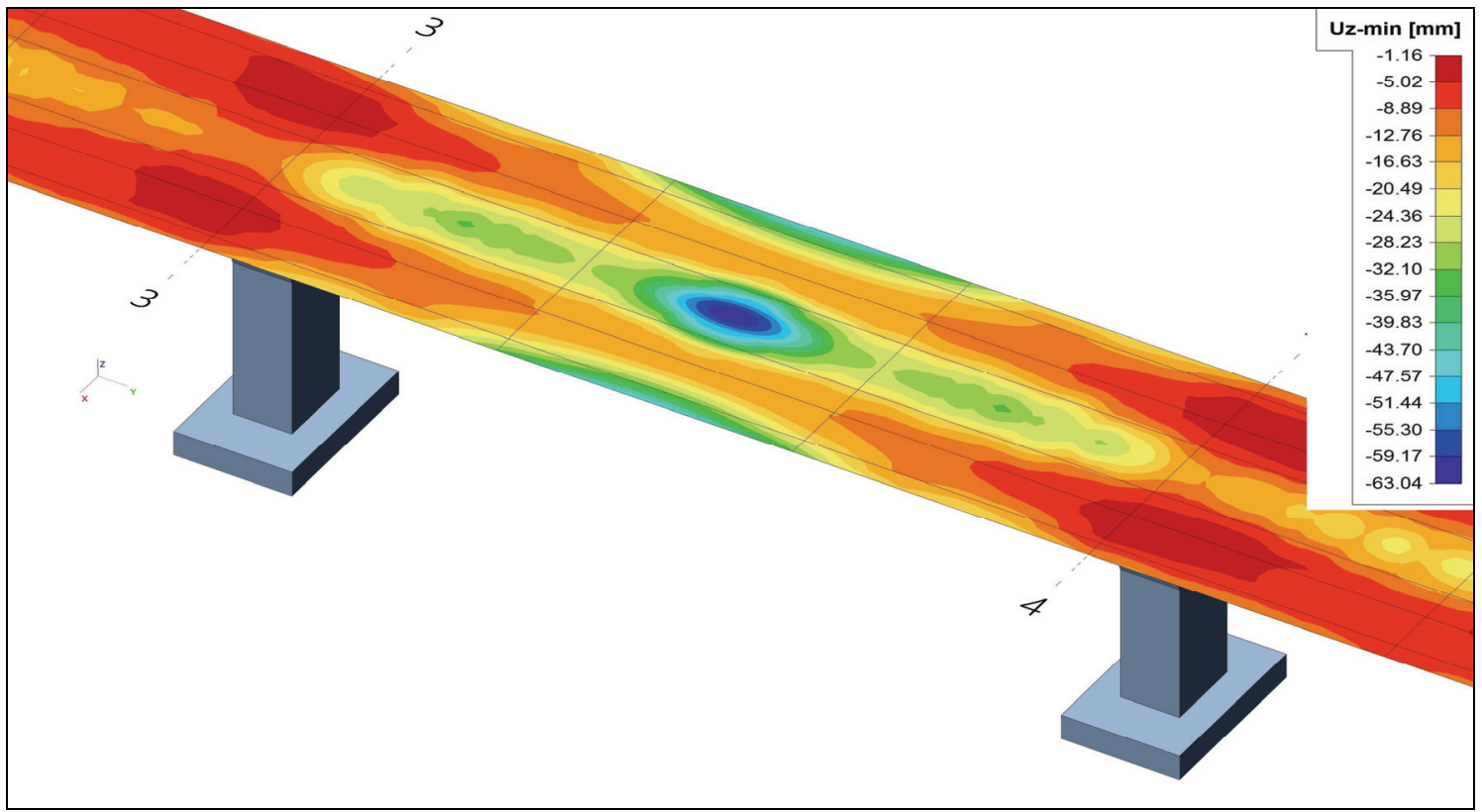

Fig. 3 Isolines of vertical displacements $U_{z}$ (in direction of negative axis $z$ ).

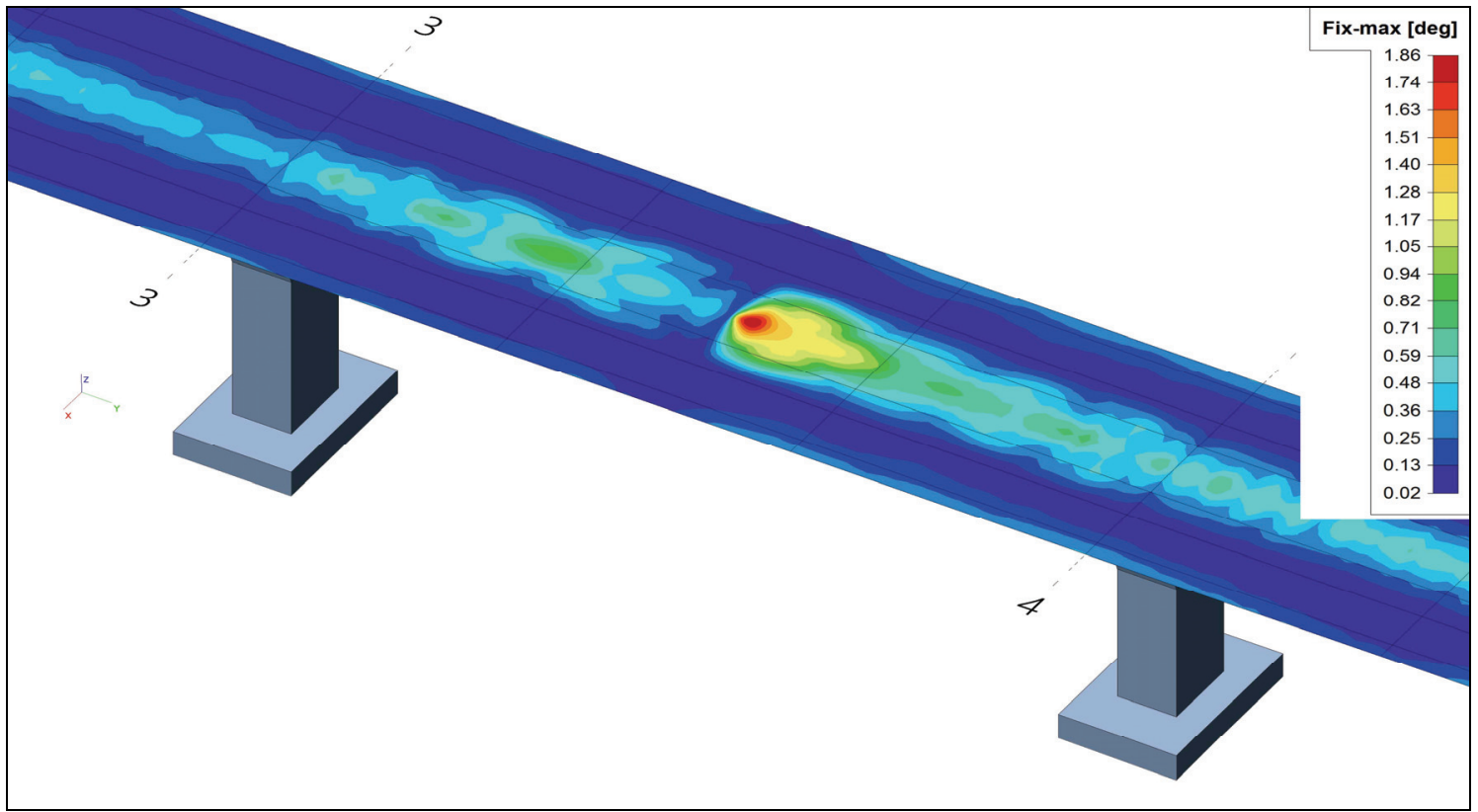

Fig. 4 Isolines of angle of rotations $F_{i x}$ round the axis $x$. 


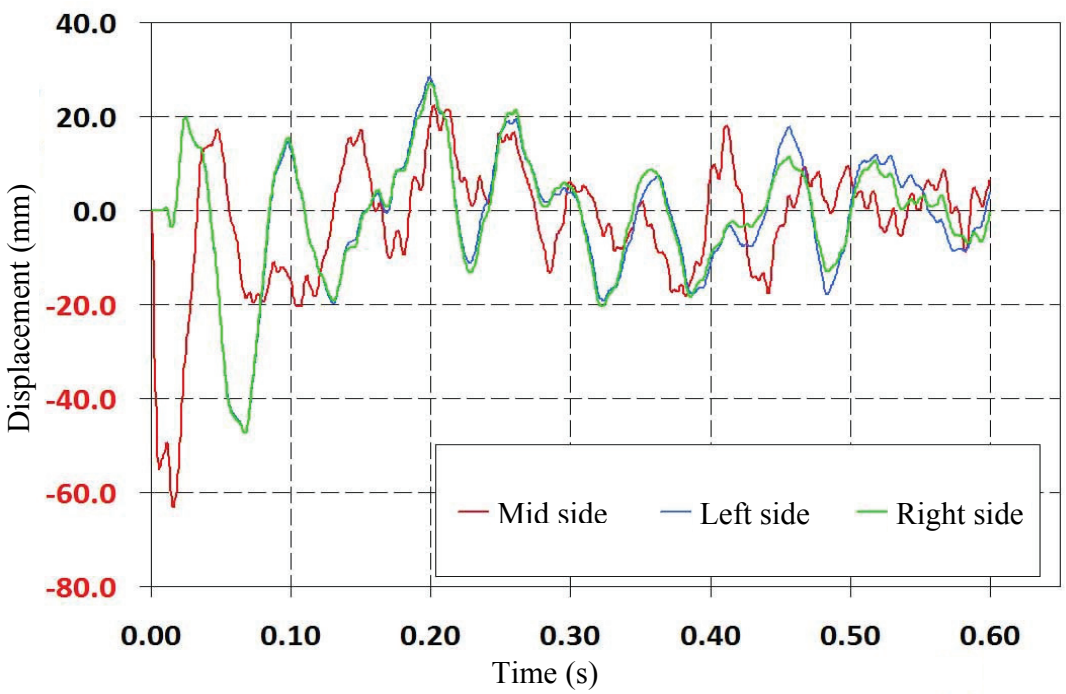

Fig. 5 Time histories of vertical displacement $U_{z}$ in selected points of bridge floor.

of the central part of the bridge cross section, the bearing capacity of the whole bridge structure may be seriously threatened under imposed vehicle load.

\section{Conclusions}

This paper is determined to the problem of an explosion and the threat to the safety of the structure due to the explosion of a explosive charge installed in a car and initiated for example on the bridge.

The explosion load is usually burdened with a number of uncertainties, related to determining the amount of explosive medium, its location in relation to the loaded structure, and the conditions in the surroundings. These load effects were derived by the authors based on the experimental results of small charge explosions. They may be used for an engineering estimation of the probable blast loads. This methodology enables us to determine with sufficient accuracy the time course of the impacting shock wave and its interaction with the structure itself.

The effect of ductility factor of structure and strain rate of concrete material on the analysis methodology is discussed. The approximation of strain rate by various strengthening factors is calculation friendly and usually safety enough with regard to uncertainties of input data, especially to location and parameters of blast wave.

The authors have used limit rotation values (angle of failure) determined experimentally on the basis of the explosion load of masonry, reinforced concrete and window glass plates, as an efficient method for response assumption. Evaluating a structure on the basis of the limit rotation is a methodology under development at present, and is in accordance with recent research trends [11] for structure loaded by blast wave of explosion.

A reinforced concrete bridge structure has been used as an example for determining and documenting the load due to a blast effect. The bridge response is assessed on the basis of the results of a 3D dynamic calculation using displacements and rotation of the cross section parts of this structure.

The results for the response of the bridge to this load are presented in parts, together with the principles for evaluating the structure according to the displacements and to the angle of failure corresponding to the given explosion load.

\section{Acknowledgments}

The study is based on outcomes of the research project VG20122015089 supported by the Ministry of the Interior of the Czech Republic, for which the authors would like to thank the ministry. 


\section{References}

[1] Makovička, D., and Janovský, B. B. 2008. Handbook of Explosion Protection for Buildings. Prague: CTU (Czech Technical University) Publishing House. (in Czech)

[2] Makovička, D., and Makovička, D. 2012. "Blast Resistant Design and Limits of the Response of a Structure to an External Explosion.” In Structures Under Shock and Impact XII, edited by Schleyer, G., and Brebbia, C. A. Southampton: WIT Press.

[3] Makovička, D., and Makovička, D. 2015. "Structure Response under Blast Wave Load." Presented at COMPDYN (International Conference on Computational Methods in Structural Dynamics and Earthquake Engineering), 5th Thematic Conferences of the ECCOMAS (European Community on Computational Methods in Applied Sciences), Crete Island, Greece.

[4] Makovička, D. 1999. "Failure of Masonry under Impact Load Generated by an Explosion." Acta Polytechnica 39 (1): 63-91.

[5] Zheng, R., Zohrevand, P., Erdogan, H., and Mirmiran, A. 2014. "Performance of FRP-Retrofitted Concrete Bridge
Columns under Blast Loading." Journal of Computational Methods and Experimental Measurements 2 (4): 346-61.

[6] Makovička, D., and Makovička, D. 2014. "Blast Resistant Design of Structure to Terrorist Explosion." In Proceeding of 9th EURODYN (International Conference on Structural Dynamics), 3519-24.

[7] Dept. of Defense. 2005. UFC (Unified Facilities Criteria) 4-023-03: Design of Buildings to Resist Progressive Collapse. Washington, D.C.: Dept. of Defense.

[8] Czech Standard Institute. 1977. ČSN 730032 (Czech Standard): Calculation of Building Structures Loaded by Dynamic Effect of Machines. Prague: Czech Standard Institute. (in Czech)

[9] British Standard Institution. 1990. CEB-FIP: Design of Concrete Structures, CEB-FIP Model-Code. London: British Standard Institution.

[10] Soroushian, P., and Choi, K. 1987. "Steel Mechanical Properties at Different Strain Rates." Journal of Structural Engineering 113 (4): 663-72.

[11] McCann, D. M., and Smith, S. J. 2007. "Blast Resistant Design of Reinforced Concrete Structures." Structure Magazine (April): 22-6. 